Research Article

\title{
Study on Rock-Breaking Depth and Damage Area under Particle Jet Impact
}

\author{
Fushen Ren $\left(\mathbb{D},{ }^{1}\right.$ Tiancheng Fang $\mathbb{D}^{1}{ }^{1}$ and Xiaoze Cheng ${ }^{2}$ \\ ${ }^{1}$ School of Mechanical Science and Engineering, Northeast Petroleum University, Daqing 163318, Heilongjiang, China \\ ${ }^{2}$ The China National Petroleum Corporation, Beijing 100724, China \\ Correspondence should be addressed to Fushen Ren; renfushen@126.com and Tiancheng Fang; fangtc211@163.com
}

Received 22 October 2019; Revised 30 May 2020; Accepted 17 June 2020; Published 1 September 2020

Academic Editor: Marco Lepidi

Copyright (c) 2020 Fushen Ren et al. This is an open access article distributed under the Creative Commons Attribution License, which permits unrestricted use, distribution, and reproduction in any medium, provided the original work is properly cited.

Particle jet impact drilling technology is an efficient method which mainly uses high-velocity particles to break rock. As the important criterion for evaluating rock-breaking effect, rock-breaking depth and damage area were studied in this paper. Firstly, a particle jet impact rock-breaking test device was developed, and laboratory experiments have been carried out. Then, based on the spherical cavity expansion theory, the mathematical model of rock-breaking depth and damage area under particle jet impact was established. Afterward, the effect of water-jet impact velocity, impact angle, and particle diameter on rockbreaking depth and damage area was analyzed by comparing experimental results and mathematical calculation. The results show that rock-breaking depth and damage area would increase with increase of water-jet impact velocity and decrease slightly with increase of particle diameter. And the combination of $8^{\circ}$ and $20^{\circ}$ is recommended for nozzle layout. The experimental results and mathematical calculation are basically consistent, which could verify the correctness of the mathematical model. The study has significance for development and application of particle jet impact rock-breaking technology and perfection of theoretical research.

\section{Instruction}

With the depletion of shallow petroleum resources, deep oil and gas reservoirs in complex strata have gradually become the focus of petroleum exploration. Hard and grindingresistant rock stratum drilling technology of deep and ultradeep well would become the technical research direction tackled in the future of China [1]. Particle jet impact drilling technology is a high-efficiency noncontact rockbreaking process which is mainly based on subsonic particle impact and break rock, while being supplemented by highvelocity water jet and mechanical bit. The work principle is that a certain ratio of steel particles is added to drilling fluid and particles are accelerated by special nozzle to form subsonic particle jet. High-velocity particle jet would impact on rock surface to form drilling groove and release the compaction stress inside of rock, which can reduce rock strength. The rock that has formed drilling rings is easier to crush under the grinding action of drill bits, thus realizing drilling rapidly. Recently, it has been gradually applied in oil field and coalfield exploitation [2].

In rock-breaking field, the methods of water jet, laser, abrasive jet, undercutting TBM (tunnel boring machine), and multistage TBM cutterhead are proposed and studied. Ramezanzadeh et al. reviewed the new methods and mechanical devices of underground hard rock mining and evaluated the potential of such methods and researches [3]. Lu et al. analyzed the damage evolution process under impact of ultra-high-pressure water jet and established the relationship between rock macrofracture law and microfailure mechanism [4]; also, the effects of water and supercritical carbon dioxide on rock fracture and permeability evolution were studied [5]. Geng et al. proposed the free-surface-assisted rock-breaking method based on multistage TBM cutterhead and analyzed the rock failure mechanism and rock-breaking efficiency through experiment and numerical simulation [6, 7]. Based on $\mathrm{JH}-2$ model and tensile cracking softening model as rock constitutive model, Xia et al. analyzed the dynamic fracture 
process of rock [8]. Rupam et al. used continuous water jet and ultrasonic pulse water jet to study the depth, width, and volume erosion of granite, which proved the advantages of pulse water jet in parameters and cost [9].

In engineering practice and application of particle jet impact rock-breaking technology, Particle Drilling Technology Inc. (PDTI) of USA has carried out many laboratory tests and improved field tests, which show that particle jet impact drilling technology could achieve rapid drilling in hard formations [10]. The successful application of particle impact rock-breaking laboratory test and field experiment shows that the rock-breaking technology has broad application prospects in improving drilling speed [11-14]. In theoretical research of rock broken, many professors have studied the theory of rock breaking by high-pressure water jet and particle jet impingement [15-20]. The studies of single particle and multiparticle impact rock were carried out with numerical simulation and experiments $[21,22]$. The dynamic analysis of rock damage during rock-breaking process was carried out, and the effect of different parameters on rock-breaking process was studied [23, 24]. The mathematical model and experimental study of particle jet impact rock breaking were carried out, and the effect factors of rock breaking were analyzed $[25,26]$.

In the previous research of our research group, the experimental research on the design of rock breaking the experimental device was introduced and particle jet impact rock-breaking experiment was carried out [14, 27]. Meanwhile, the flow field and size optimization of nozzle were studied based on computational fluid dynamics [28], and rock-breaking process and broken depth were simulated to reveal rock-breaking mechanism based on the SPH-FEM method [29, 30].

At present, theoretical study in particle jet impact rockbreaking field was carried out widely with simulation method; however, it is less with mathematical modeling method, especially in aspect of rock-breaking depth and damage area. The purpose of this paper is to study rockbreaking depth and damage area under particle jet impact, so as to realize the analysis and evaluation of rock-breaking effect. Through comparison and verification of mathematical model and laboratory experiment, the effect of different jet parameters on rock-breaking depth and damage area would be analyzed, and the correctness of mathematical model would be verified, which can realize quantitative analysis of jet parameters on rock-breaking effect and prediction of rock-breaking depth and area but also can provide support for the development of rock-breaking theory and the engineering application of particle jet impact drilling technology.

\section{Laboratory Experiment}

According to principle of particle jet impact drilling rockbreaking technology, the experimental device of particle jet impact rock breaking was developed. The rock-breaking experiments of particle jet-coupled impact were carried out in Engineering Center of Northeast Petroleum University
$[18,27]$. The effects of water-jet impact velocity, impact angle, and particle diameter on rock-breaking depth and damage area were measured and studied.

2.1. Experimental Device and Work Process. In order to simulate the working conditions of particle jet impact drilling and reflect the influence of different factors on impact depth and damage area, the laboratory experimental device for particle jet impact rock breaking was self-developed, as shown in Figure 1.

The power module is mainly composed of plunger pump and control cabinet, which can provide hydraulic power for experimental device. The water circulation module can realize the circulation of water and separation of metal particles from rock debris, so as to avoid waste of resources. The particles injection model mainly realizes uniform injection of steel particles into pipeline, and the simulated bottomhole module is used to simulate the rock bottom hole. The simulated top drive module is mainly including rotating mechanism and lifting mechanism and mainly composed of servo motor, gear transmission mechanism, ball screw, lifting platform, and drill pipe. In the simulated top drive model, the movement of drilling bit includes rotary cutting and axial feeding. The rotation speed of rotary cutting is mainly driven by servo motor to drive the gear transmission mechanism and then drive drilling string and bit to rotate. The axial feeding speed is realized by servo motor to drive the ball screw to keep the bit with constant pressure or constant feeding speed in laboratory experiment.

The workflow of indoor experiment is as follows. Before the laboratory experiment of particle jet impact rock breaking, safety check should be carried out to ensure the normal operation of all components. At the beginning of test, the high-pressure pump was opened to remove residual particles in pipeline, and the rock should be fixed to achieve an appropriate target distance. Then, the flow of plunger pump and the screw propeller speed could be set to control fluid velocity and particle ratio. Rock-breaking experiments were carried out by controlling the servo motor of the simulated top drive model and then controlling drilling speed of the bit according to experimental target. Finally, the screw propeller and high-pressure pump were closed, and the test results of rock broken samples were measured. After rock-breaking experiment, the waste materials should be sorted out, and the important parts should be maintained to facilitate the next experiment.

\subsection{Experimental Materials and Rock-Breaking Samples.} The medium hard granite with size of $250 \mathrm{~mm}$ $\times 250 \mathrm{~mm} \times 100 \mathrm{~mm}$ and steel particles of diameter with $0.8 \mathrm{~mm}, 1.0 \mathrm{~mm}, 1.2 \mathrm{~mm}$, and $1.4 \mathrm{~mm}$ were used in process of particle jet impact rock breaking. The failure of rock samples under different working conditions (impact angle is $0^{\circ}, 8^{\circ}, 20^{\circ}$, and compound angle of $8^{\circ}$ and $20^{\circ}$ ) is shown in Figure 2.

The rock-breaking samples are approximately regular in shape, and the rock-breaking depth and damage area were obtained by measuring the maximum depth and groove 


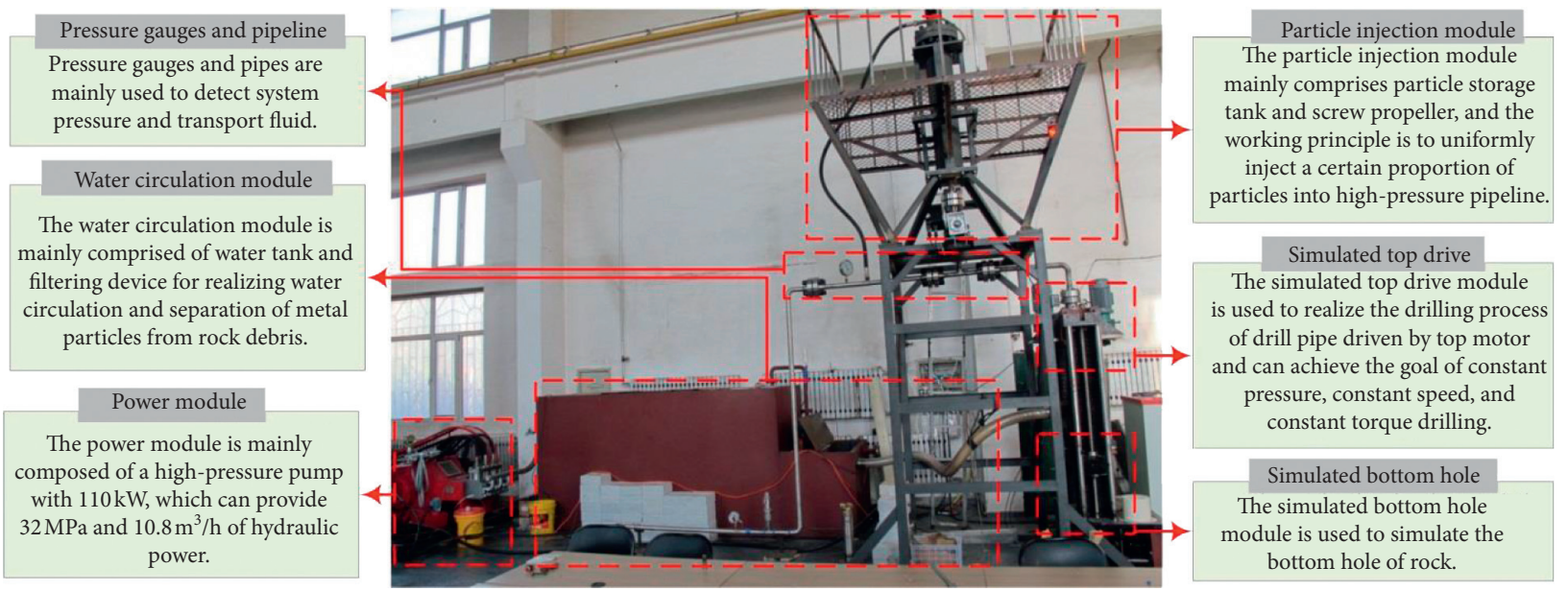

FIgURE 1: Particle jet impact rock-breaking laboratory device.
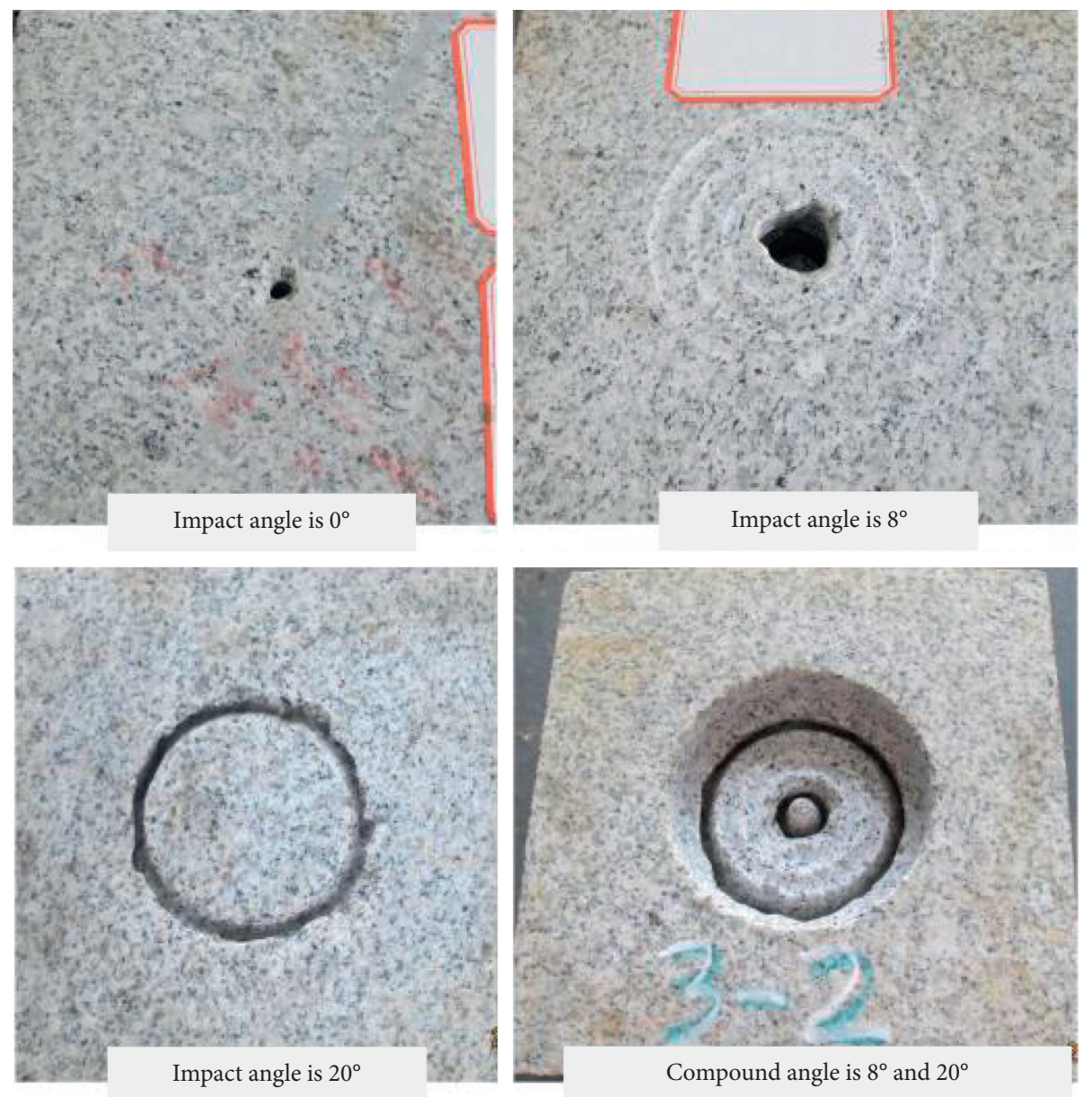

Figure 2: The rock-breaking samples.

width. The rock-breaking depth is measured by infrared distance meter based on phase method. The measurement method of damage area is shown in Figure 3, which refers to the diameter of broken hole or the width of broken groove measured with vernier caliper. For error minimization, the average value could be obtained with multiple tests and repeated measurements.

\section{Mathematical Modelling of Particle Jet Impact Rock Breaking}

When the rock in deep well is impacted by particle jet, the macroscopic parameters are rock-breaking depth and damage area. Therefore, the theoretical analysis of rockbreaking depth model and damage area model is of great 


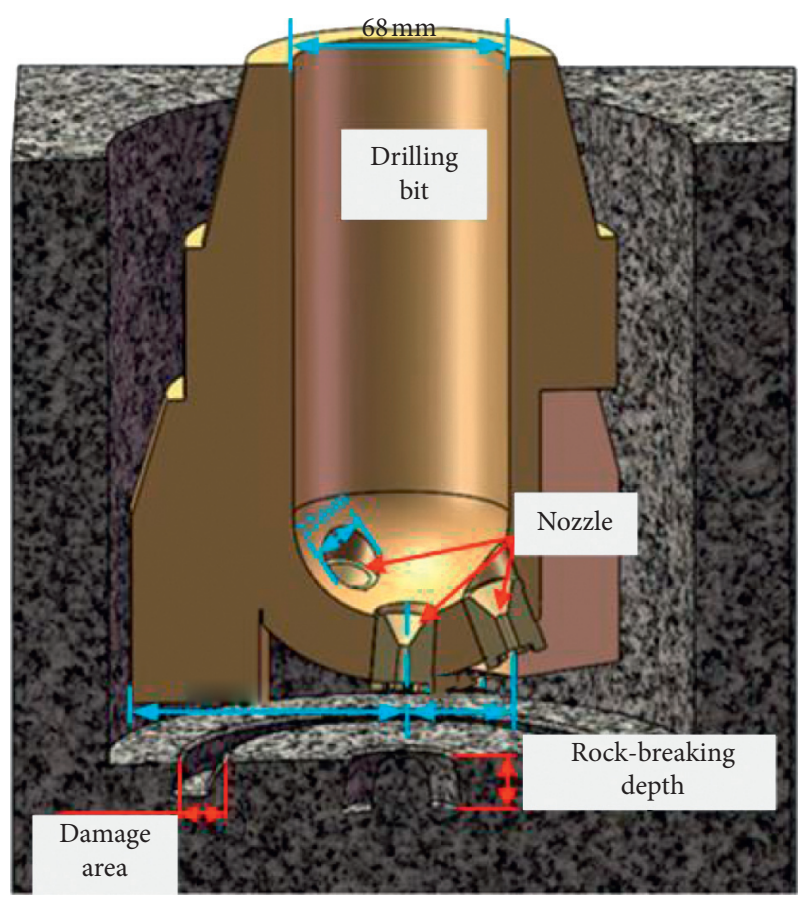

Figure 3: The measurement of rock-breaking depth and damage area.

significance to the perfection and development of particle jet impact drilling technology.

\subsection{Mathematical Models of Rock-Breaking Depth.} According to particle jet impact rock-breaking technology, the high-speed water jet carries metal particles to accelerate through the nozzle and pipelines to form high-speed particle jet, which then impacts hard rock. When particle jet accelerates through the nozzle to impact rock, the relationship between particle velocity and water-jet velocity is analyzed by regression analysis based on the previous study [28]:

$$
\left\{\begin{array}{l}
v_{p}=\eta v_{w}, \\
\eta=0.823-1.25 e^{-3} L_{0}-2.29 e^{-5} L_{0}^{2}
\end{array}\right.
$$

where $v_{p}$ is particle velocity; $\eta$ is the ratio of particle velocity and water-jet velocity; $v_{w}$ is water-jet velocity; and $L_{0}$ is the length of nozzle contraction section.

When conducting modeling and analysis, the following assumptions are made:

(1) The sustained impact pressure of high-speed water jet is transformed into constant pressure of rock

(2) The intermittent impact of particles can be regarded as cyclic and uniform impact of dynamic loads

(3) There is no initial damage of rock

The constant pressure generated by water-jet impact can be expressed as

$$
\sigma_{w}=\frac{\rho_{w} Q_{w} v_{w}}{S_{A}}
$$

where $\sigma_{w}$ is the constant pressure of water jet; $\rho_{w}$ is water-jet density; $Q_{w}$ is flow rate of nozzle; and $S_{A}$ is the collision area of water jet.

When particle jet impacts hard rock of deep well, the impact number of particles can reach thousands of times per minute. The characteristics under particle impact would show at high frequency and uniform. Therefore, the impact frequency of particles in per unit area is

$$
n=\frac{\omega_{p} t_{p}}{V_{p} n_{p}},
$$

where $n$ is the impact frequency of unit area; $\omega_{p}$ is the incorporation speed of particle; $t_{p}$ is the incorporation time of particle; $V_{p}$ is particle volume; and $n_{p}$ is the particle numbers that can be accommodated in cross-section area of nozzle outlet.

When the particle impacts rock at a certain speed, the dynamic response region of rock can be divided into cavity region, fracture region, crack region, elastic region, and undamaged region [31,32]. As shown in Figure 4, $a$ is the spherical radius of cavity region, $b$ is the outer diameter of rock fracture region, $c$ is the outer diameter of crack region, and $d$ is the outer diameter of elastic deformation region.

Because of the spherical symmetry of cavity model, the conservation equation of mass and momentum in Euler coordinates is

$$
\left\{\begin{array}{l}
\frac{\partial \rho_{r}}{\partial t}+\frac{1}{r^{2}} \frac{\partial}{\partial r}\left(\rho_{r} r^{2} v_{p}\right)=0 \\
\frac{\partial \sigma_{r}}{\partial r}+2 \frac{\left(\sigma_{r}-\sigma_{\theta}\right)}{r}=-\rho_{r}\left(\frac{\partial v}{\partial t}+v_{p} \frac{\partial v}{\partial r}\right)
\end{array}\right.
$$

where $r$ is the radial coordinate of Euler coordinates; $\rho_{r}$ is rock density; and $\sigma_{r}, \sigma_{\theta}$, and $\sigma_{\phi}$ are Cauchy components of stress and represent, respectively, radial stress, tangential stress, and circumferential stress. The cavity expansion model has spherical symmetry; therefore, the stress expression is $\sigma_{\theta}=\sigma_{\phi}$, and compressive stress is positive in direction.

The penetration depth model of spherical projectile is established based on cavity expansion theory [31], and the relationship between radial stress and impact velocity of particle is

$$
\sigma_{r}=\xi \delta_{c}+\zeta \rho_{r} v_{p}^{2}
$$

where $\delta_{c}$ is compressive strength of rock; $\xi$ and $\zeta$ are the parameters related to constitutive properties of rock, respectively; and the expression is as follows:

$$
\left\{\begin{array}{l}
\zeta=\frac{3 \delta_{t}}{E \gamma}+\frac{\eta^{*}}{\gamma}\left(1-\frac{3 \delta_{t}}{2 E}\right)^{2}+\frac{3 \eta^{*(2 / 3)}-4 \eta^{*}+\eta^{* 2}}{2\left(1-\eta^{*}\right) \gamma}, \\
\xi=\frac{2\left(1-\lg \eta^{*}\right)}{3}, \\
\gamma=\left[\left(1+\frac{\delta_{t}}{2 E}\right)^{3}-\left(1-\eta^{*}\right)\right]^{2 / 3},
\end{array}\right.
$$



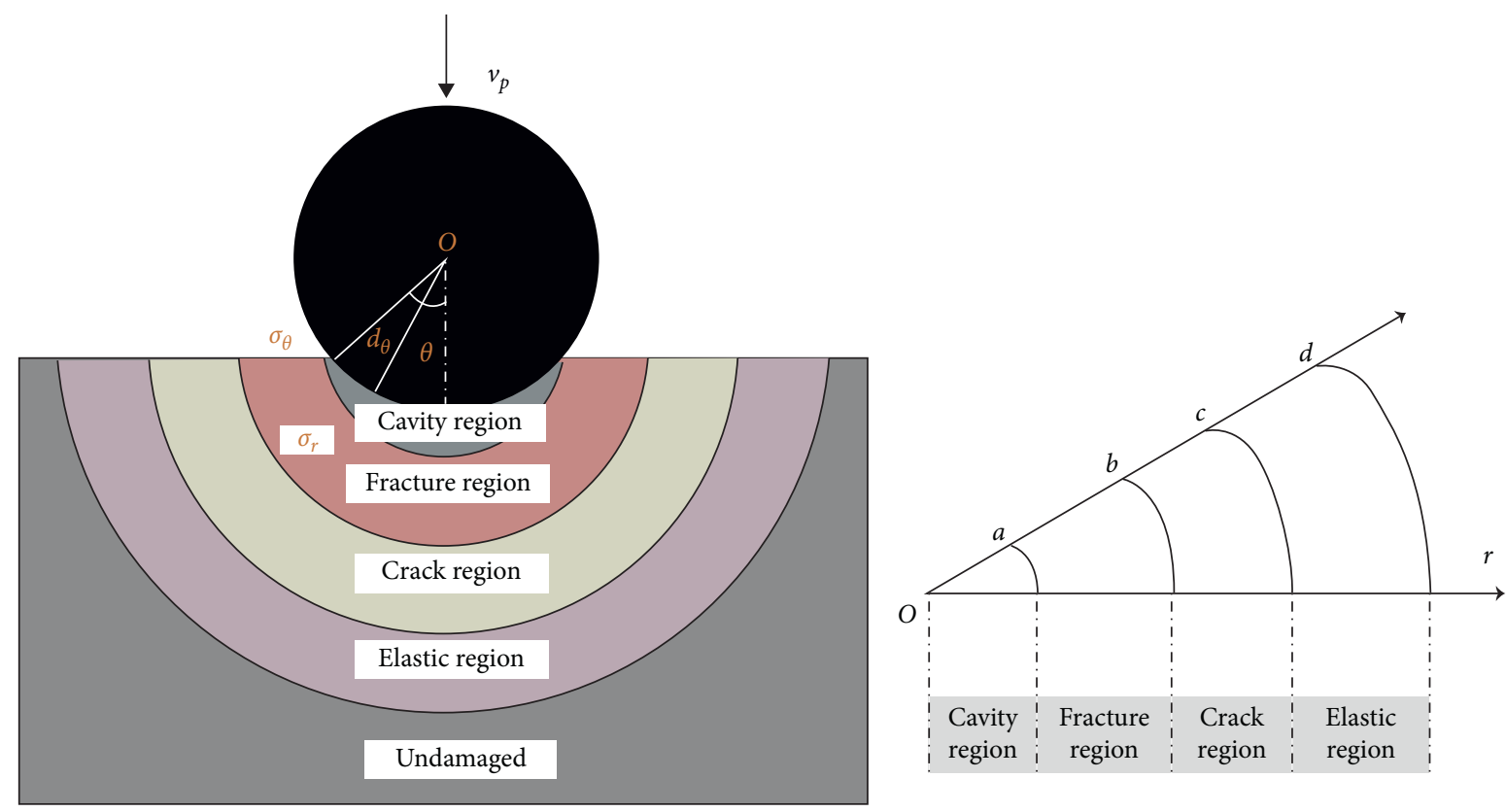

Figure 4: Dynamical damage response of rock under particle impact.

where $\eta^{*}$ is volume compaction strain of rock; $\delta_{t}$ is shear strength of rock.

When steel particle impacts on the undamaged rock, according to Coulomb friction law and principle of strain equivalence, the stress relationship with impact can be obtained:

$$
\left\{\begin{array}{l}
\sigma_{\theta}=\mu \sigma_{r}, \\
\varepsilon=\frac{\sigma_{r n}}{E_{n}}=\frac{\sigma_{r}}{E_{r}},
\end{array}\right.
$$

where $\mu$ is coefficient of sliding friction; $\varepsilon$ is elastic strain of rock; $\sigma_{r n}$ is radial stress with rock damaged; $E_{r}$ is elastic modulus of rock; and $E_{n}$ is elastic modulus with rock damaged.

Under the cyclic impact of particles, there will be destroy pits and crack damage, so the mechanical properties of damaged rock will inevitably change [33]. When the rock has been in damage state, the cumulative damage equation of rock with particle cyclic impact can be expressed:

$$
D_{n}=\alpha-\oplus \ln \left(\frac{k}{n}-p\right),
$$

where $D_{n}$ is the cumulative damage factor of rock; $\alpha$ and $₫$ express the parameters related to rock failure; and $p$ and $k$ express the parameters related to jet impact pressure.

If the rock reaches a stable damage state after $n$-times impact, the radial stress of the rock is expressed as

$$
\sigma_{r n}=\left(\xi \delta_{c}+\zeta \rho_{r} v_{p}^{2}\right)\left(1-D_{n}\right) .
$$

The steel particle impacts on rock; the force action is shown in Figure 4. According to the force state of rock element, the sum of resistance in vertical direction can be obtained:

$$
d F_{h}=\pi R^{2}\left(\sigma_{r} \sin 2 \theta+2 \sigma_{\theta} \sin ^{2} \theta\right) \mathrm{d} \theta,
$$

where $F_{h}$ is the sum of resistance in vertical direction; $R$ is particle radius; $\theta$ is the angle between microelement and $Z$ axis.

When rock is damaged under particles impact, the resistance of the rock under stable damage state can be calculated according to (10):

$$
F_{h}=\pi R^{2} \sigma_{r n} \int_{0}^{\bar{\theta}}\left(\sin 2 \theta+2 \mu \sin ^{2} \theta\right) \mathrm{d} \theta
$$

According to Newton's third law, the relationship between rock-breaking depth and particle velocity in the process of particle impact rock is as follows:

$$
m_{p} \frac{\mathrm{d} v_{p}}{\mathrm{~d} t}=m_{p} \frac{\mathrm{d} h_{p n}}{\mathrm{~d} t} \frac{\mathrm{d} v_{p}}{\mathrm{~d} h_{p n}}=m_{p} v_{p} \frac{\mathrm{d} v_{p}}{\mathrm{~d} h_{p n}}=-F_{h},
$$

where $m_{p}$ is the mass of single particle.

After impact of n-times, the rock-breaking depth of single particle under stable damage state can be obtained by (12):

$$
h_{p n}=\int_{\eta v_{f}}^{0} \frac{-m v \mathrm{~d} v}{\pi R^{2} \sigma_{r n} \int_{0}^{\bar{\theta}}\left(\sin 2 \theta+2 \mu \sin ^{2} \theta\right) \mathrm{d} \theta} .
$$

For high-frequency and high-speed impact of particles, the rock-breaking depth in a certain period of time can be derived from (13):

$$
H=\frac{Q_{w} \omega_{p} t_{p} \cos \beta}{V_{p} n_{p}} \int_{\eta v_{f}}^{0} \frac{-m v \mathrm{~d} v}{\pi R^{2} \sigma_{r n} \int_{0}^{\bar{\theta}}\left(\sin 2 \theta+2 \mu \sin ^{2} \theta\right) \mathrm{d} \theta},
$$

where $\beta$ is the impact angle, and when particle water-jet impacts on the rock vertically, $\beta=0$. 
3.2. Mathematical Models of Damage Area. Damage area, as the one of main indexes in particle jet impact drilling, mainly includes microdamage and macrofailure. The damage zones of rock under particle jet impact mainly include fracture region, crack region, and water-jet impact damage region, as shown in Figure 4. Macroscopic failure area of rock is mainly composed of fracture region and water-jet impact damage region, and microcosmic damage mainly refers to crack region.

3.2.1. Elastic Region $(c<r<d)$. For spherically symmetric cavity expansion model, the stress-displacement relationship is expressed as

$$
\left\{\begin{array}{l}
\sigma_{r}=-\frac{E_{n}}{\left(1+\mu_{r}\right)\left(1-2 \mu_{r}\right)}\left[\left(1-\mu_{r}\right) \frac{\partial u_{r}}{\partial r}+2 \mu_{r} \frac{u_{r}}{r}\right], \\
\sigma_{\theta}=-\frac{E_{n}}{\left(1+\mu_{r}\right)\left(1-2 \mu_{r}\right)}\left[\mu_{r} \frac{\partial u_{r}}{\partial r}+\frac{u_{r}}{r}\right],
\end{array}\right.
$$

where $u_{r}$ is the radial displacement; $\mu_{r}$ represents Poisson's ratio of rock.

The stress equilibrium equation of spherical shell element is

$$
\sigma_{\theta}-\sigma_{r}=\frac{r}{2} \frac{\mathrm{d} \sigma_{r}}{\mathrm{~d} r}, \quad(c<r<d) .
$$

The joint solution of equations (15) and (16) can be obtained:

$$
\left\{\begin{array}{l}
\frac{r}{2} \frac{\partial^{2} u_{r}}{\partial r^{2}}+\frac{\partial u_{r}}{\partial r}-\frac{u_{r}}{r}=0 \\
\left.\sigma_{\theta}\right|_{r=c}=-\delta_{t}, \\
\left.\sigma_{r}\right|_{r=d}=0
\end{array}\right.
$$

According to the second-order homogeneous differential equation and the solving method of Riccati equation, integral transformation of equation (7) is carried out [34], and the expression of elastic displacement is obtained:

$$
u_{r}=\frac{\delta_{t} c^{3}}{E_{n}\left(2 c^{3}+d^{3}\right)}\left[2\left(1-2 \mu_{r}\right) r+\left(1+\mu_{r}\right) \frac{d^{3}}{r^{2}}\right] \text {. }
$$

From equation (9) of displacement formula, the expression in elastic region can be derived. When $r=d$, the outer diameter of elastic region can be obtained:

$$
\left(1-\frac{c}{d}\right)\left(2+\left(\frac{d}{c}\right)^{3}\right)=\frac{3 \delta_{t}}{E_{n}}\left(1+\mu_{r}\right)
$$

3.2.2. Crack Region $(b<r<c)$. In process of particle waterjet impact rock breaking, many cracks are easy to occur in crack region due to the existence of tensile stress, and it can be regarded as the extension of elastic deformation region. The radial and circumferential stresses in crack region can be obtained by integral of equation (17), and the boundary conditions are

$$
\begin{aligned}
& \left.\sigma_{r}\right|_{r=b}=-\delta_{c}, \\
& \left.\sigma_{\theta}\right|_{r=c}=0 .
\end{aligned}
$$

For the region where cracks occurred, only radial stress is generated due to the existence of radial cracks. According to equation (17) and boundary equation (20), it can be obtained that

$$
\sigma_{r}=\frac{\delta_{c} b^{2}}{r^{2}}
$$

The displacement of crack region is obtained by integral transformation:

$$
u_{r}=\frac{1}{E_{n}} \frac{b^{3} c^{3}}{2 c^{3}+b^{3}}\left[\left(1+\mu_{r}\right)\left(\delta_{t}+\delta_{c}\right) \frac{1}{r^{3}}+\left(\frac{\delta_{c}}{c^{3}}-\frac{2 \delta_{t}}{b^{3}}\right)\left(1-2 \mu_{r}\right) r\right] .
$$

Then, the radius of crack region can be obtained by deduction:

$$
\begin{aligned}
\left(2 c^{3}+b^{3}\right)(c-b)= & b^{3}\left(1+\mu_{r}\right)\left(\frac{\delta_{t}+\delta_{c}}{E_{n}}\right) \\
& +c\left(1-2 \mu_{r}\right)\left(\frac{b^{3} \delta_{c}-2 c^{3} \delta_{t}}{E_{n}}\right)
\end{aligned}
$$

3.2.3. Fracture Region $(a<r<b)$. When the radial stress in crack region fails in two orthogonal circular directions, compressive strength of rock increases, and its cohesive strength is zero, so that rock is broken, that is, fracture region.

The constant $\lambda$ is introduced to express relationship between compressive stress and shear stress. For the spherically symmetric cavity expansion model, the following formula is considered:

$$
\frac{\sigma_{r}-\sigma_{\theta}}{2}=\lambda \frac{\sigma_{r}+2 \sigma_{\theta}}{3} .
$$

Combining equations (24) and (17), the radial stress in fracture region can be obtained by integral calculation:

$$
\sigma_{r}=\delta_{c}\left(\frac{b}{r}\right)^{(12 \lambda / 4 \lambda+3)}
$$

When steel particles impact on rock, assuming that impact area flows along the normal direction of cavity surface, relationship between the radius of cavity region and fracture region can be obtained. The radius of fracture region can be obtained by Taylor expansion with method of ignoring higher-order terms:

$$
3 b^{2} \frac{\delta_{c}}{E_{n}} \mathrm{~d} b=\frac{a^{3}}{R} \mathrm{~d} a
$$


3.2.4. Cavity Region $(r<a)$. In the process of particle impact rock breaking, the pressure of particle on rock can be calculated by equation (25) according to the continuity condition:

$$
\sigma_{\text {cavity }}=\left.\sigma_{r}\right|_{r=a}=\delta_{c}\left(\frac{b}{a}\right)^{(12 \lambda / 4 \lambda+3)} .
$$

The steel particle is regarded as rigid bodies under impact into rock target at a certain speed. The expression between cavity region radius and particle velocity can be obtained according to kinetic energy transformation and contact stress [35] in process of particle impact rock:

$$
4 a^{3}=\left(\frac{1-\mu_{p}^{2}}{E_{p}}+\frac{1-\mu_{r}^{2}}{E_{n}}\right)^{(3 / 5)}\left(\frac{125}{\sqrt{3}}\right)^{(2 / 5)}\left(m_{p} v_{p}^{2}\right)^{(3 / 5)} R^{(6 / 5)} .
$$

The Runge-Kutta method could be used to solve formulas (19), (23), (26), and (28) iteratively, and the radii of different response regions can be obtained.

3.2.5. Water-Jet Impact Damage Region. The impact of highvelocity water jet would not only remove debris from fractured region but also cause secondary failure to rock in crack region and enlarge the fractured region. According to the principle of stress superposition, the stress of water-jet impact is superimposed on basis of stress in crack region [25]. If superimposed stress exceeds the compressive strength of rock, cracked region would be transformed into fractured region, and the damage region of water-jet is marked as $b_{j}$.

The radial stress at any position in crack region under particle impact can be calculated by (17), and the stress under water-jet impact can be calculated by equation (2). When $r=b+b$, the superimposed stress equals compressive strength, and it can be solved with following equation:

$$
\left.\sigma_{d}\right|_{r=b+b_{j}}=\delta_{c}\left(\frac{b}{b+b_{j}}\right)^{12 \lambda /(4 \lambda+3)}+\sigma_{j}=\delta_{c},
$$

where $\sigma_{d}$ is the superimposed stress.

The damage region of high-velocity water jet can be obtained on the basis of equation (28). Therefore, the damage area $D_{s}$ under coupling impact of single particle and water jet should include particle impact breakage zone and water-jet impact damage zone:

$$
D_{s}=2 b+2 b_{j} .
$$

For multiparticle jet coupling impact, it can be considered that it is the uniform impact process in probability. When particles are ejected through nozzle, the damage area under particle jet impact is shown in Figure 5. Supposing that particle jet impacts rock at vertical angle, the damage area mainly includes distance between the particle centroid at the limit position, the cavity region, and the fragmentation area, and the damage area with particle jet impact can be expressed as

$$
D_{d n}=d_{n}-2 R+2 b+2 b_{j},
$$

where $d_{n}$ is the nozzle diameter.

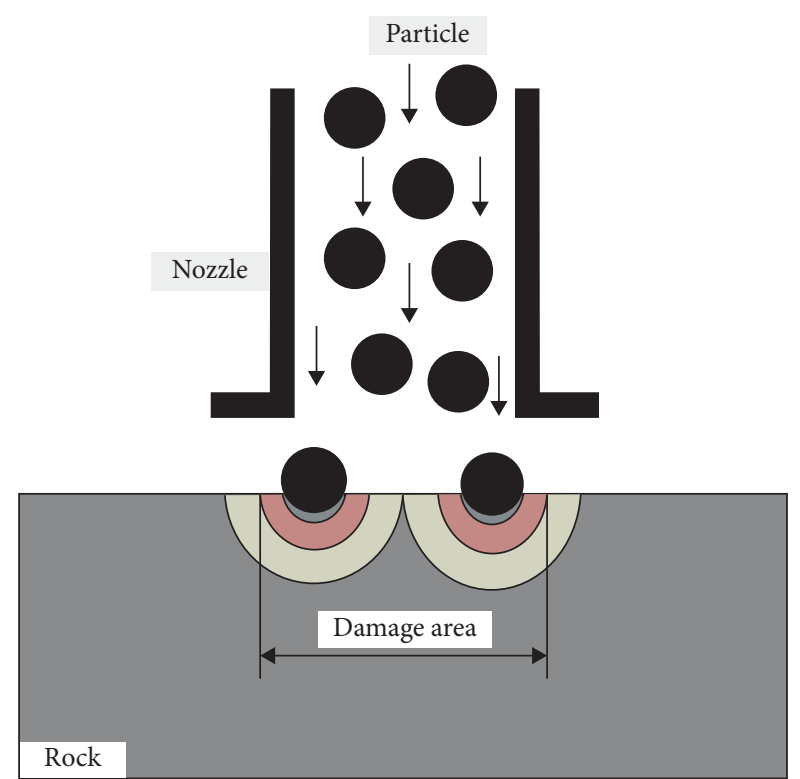

Figure 5: The damage area under multiparticles jet impact.

When the nozzle rotates with a certain angle $\beta$ and multiparticles jet coupling impact rock, the damage area corresponds to the width of the annular fracture groove (Figure 6), and the expression is as

$$
D=\frac{d_{n}-2 R+2 b+2 b_{j}}{\cos \beta} .
$$

With mathematical modeling of rock-breaking depth and damage area, theoretical analysis of rock broken effect of particle jet-coupled impact under different working conditions could be realized.

\section{Calculation Analysis and Discussion}

In the process of particle jet impact drilling, water-jet impact velocity, particle diameter, and impact angle would play an important role in rock-breaking depth and damage area. According to the mathematical model established previously, rock-breaking depth and damage area can be calculated and analyzed with the mechanical properties of particle water jet and rock, as shown in Table 1. The correctness of theoretical model is verified by comparing model calculation with experimental results, and the influence laws of different parameters are studied.

4.1. Water-Jet Impact Velocity. In process of acceleration and transmission of particle water jet, high-speed steel particles mainly rely on the carrying action of water jet, so the waterjet impact velocity would play the vital effect on rockbreaking effect. With particle water-jet impact rock vertically, while particle diameter and particle ratio is constant, the study on rock-breaking depth and damage area of waterjet impact velocity is carried out, and the comparison between mathematical model calculation and experimental result is shown in Figures 7 and 8. 


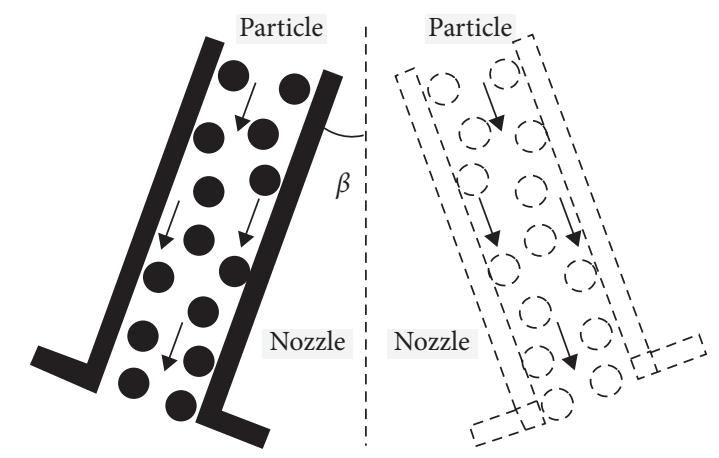

Rock

Figure 6: Particle jet impact rock with inclined rotation.

TABLE 1: The mechanical properties of particle, water-jet, and rock.

\begin{tabular}{lccc}
\hline$\rho_{r}\left(\mathrm{~kg} / \mathrm{m}^{3}\right)$ & $E_{r}(\mathrm{GPa})$ & $\delta_{c}(\mathrm{MPa})$ & $\delta_{t}(\mathrm{MPa})$ \\
\hline 2650 & 16.6 & 50 & 5.5 \\
\hline$\rho_{p}\left(\mathrm{~kg} / \mathrm{m}^{3}\right)$ & $E_{p}(\mathrm{GPa})$ & $\rho_{w}\left(\mathrm{~kg} / \mathrm{m}^{3}\right)$ & $Q_{w}\left(\mathrm{~m}^{3} / \mathrm{h}\right)$ \\
\hline 7850 & 230 & 1000 & $0-10.5$ \\
\hline$\mu_{r}$ & $\eta^{*}$ & $\mu_{p}$ & $\mu$ \\
\hline 0.30 & 0.1 & 0.25 & 0.04 \\
\hline
\end{tabular}

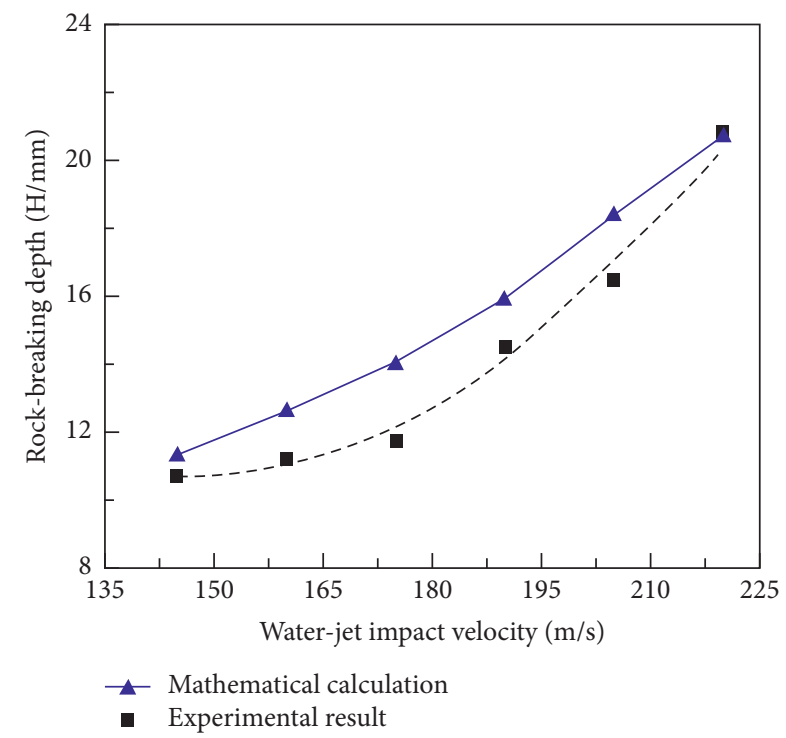

Figure 7: Effect of water-jet impact velocity on rock-breaking depth (test time with $10 \mathrm{~s}$; particle diameter with $1.0 \mathrm{~mm}$; impact angle with $0^{\circ}$ ).

According to the comparative analysis between mathematical calculation and experimental result, with increase of water-jet impact velocity, the rock-breaking depth and damage area present an increasing trend. For rock-breaking depth, with increase of water-jet impact velocity, the depth represents the trend of slowness and then rapidity, while the change trend of damage area shows a trend of rapid increase and then slow growth. The main reason is that particle impact velocity mainly depends on the acceleration of water jet; therefore, water-jet impact velocity can determine the rock broken effect, and the higher the water-jet impact velocity, the

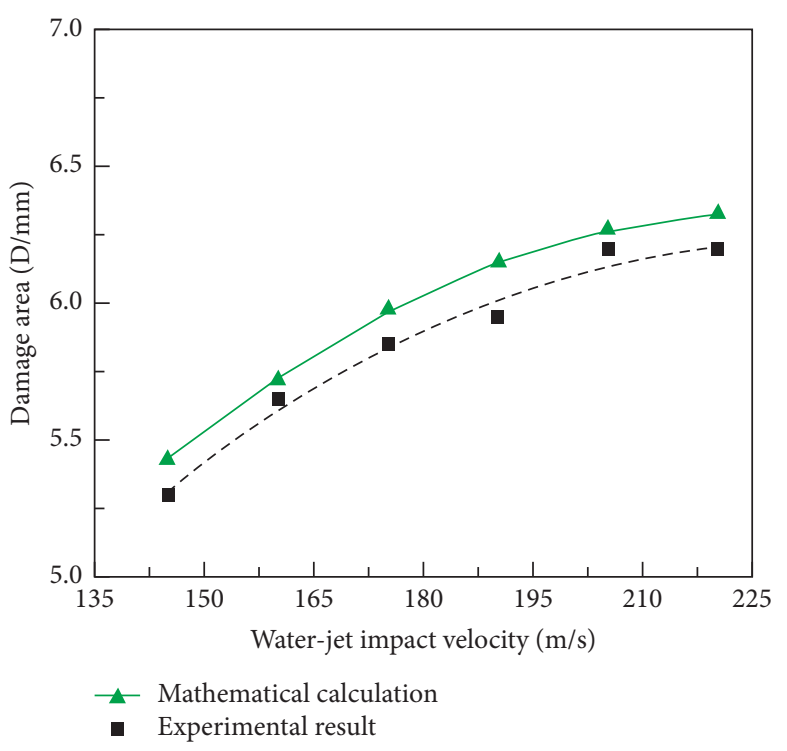

FIGURE 8: Effect of water-jet impact velocity on damage area (test time with $10 \mathrm{~s}$; particle diameter with $1.0 \mathrm{~mm}$; impact angle with $0^{\circ}$ ).

better the rock-breaking effect. For quantitative analysis, when water-jet impact velocity reaches $205 \mathrm{~m} / \mathrm{s}$, damage area is about $6.2 \mathrm{~mm}$ under vertical impact, the removal rate of rock cuttings with single nozzle can reach $0.17 \mathrm{~L} / \mathrm{h}$, and the average penetrating speed is about $1.6 \mathrm{~mm} / \mathrm{s}$, which is equivalent to drilling speed of $5.7 \mathrm{~m} / \mathrm{h}$, which exceeds mechanical drilling speed about three times. According to working conditions and the change rule of rock-breaking depth and damage area, water-jet impact velocity of $200 \mathrm{~m} /$ $\mathrm{s} \sim 210 \mathrm{~m} / \mathrm{s}$ can be satisfied to the requirement of rockbreaking technology.

4.2. Impact Angle. Reasonable layout of nozzles on drilling bit is needed in order to achieve high-efficiency rockbreaking results. Therefore, it is important to study impact angle (the angle of nozzles) for rock-breaking effect to achieve hard rock broken rapidly in deep well. Experiments were carried out on the variable of impact angle, and the change curves of rock-breaking depth and damage area at different impact angles of single nozzle are shown in Figures 9 and 10, respectively.

From comparative analysis results, it could be conclude that damage area increases with the increase of impact angle, while rock-breaking depth generally represents the decreasing trend. Meanwhile, it could be seen that mathematical calculation results are basically consistent with experimental results. The average error of mathematical calculation and experiment result is less than $5 \%$, and the maximum error of rock-breaking depth occurs with impact angle of $0^{\circ}$. The main reason is that the presence of reflux flow in vertical impact would result in loss of energy, and reflux flow was not taken into account in process of mathematical calculation. When the impact angle exceeds $8^{\circ}$, the error between experiment and mathematical calculation is small, and the trend is basically consistent. 


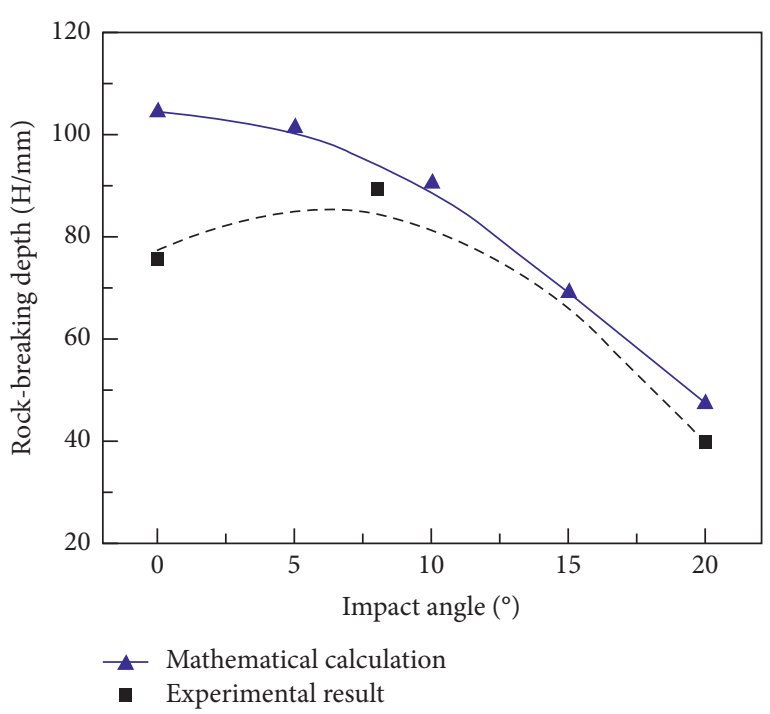

FIGURE 9: Effect of impact angle on rock-breaking depth (test time with $60 \mathrm{~s}$; particle diameter with $1.0 \mathrm{~mm}$; water-jet impact velocity with $205 \mathrm{~m} / \mathrm{s}$ ).

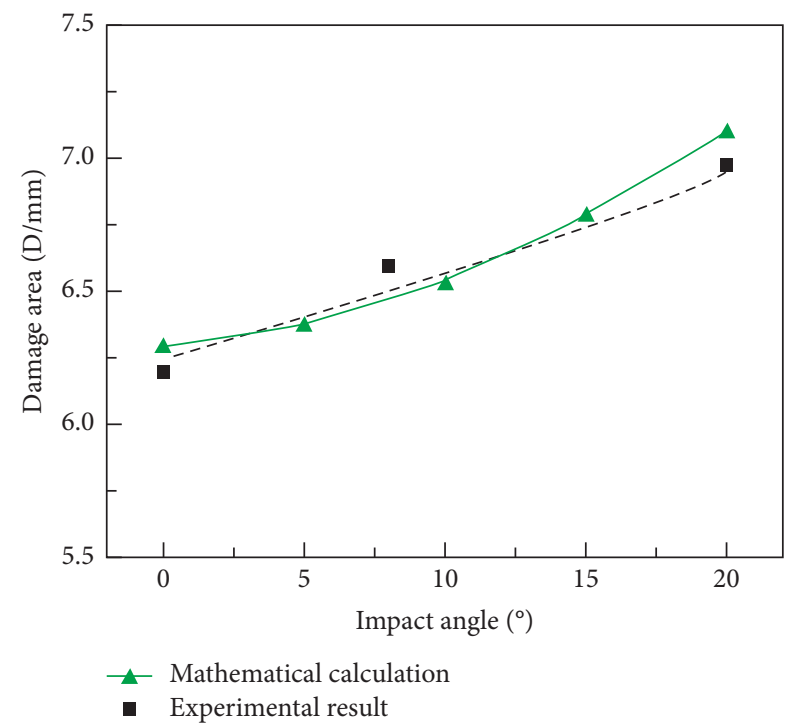

FIGURE 10: Effect of impact angle on damage area (test time with $60 \mathrm{~s}$; particle diameter with $1.0 \mathrm{~mm}$; water-jet impact velocity with $205 \mathrm{~m} / \mathrm{s}$ ).

According to particle jet impact rock-breaking technology, the rock in deep well is mainly impacted and cut to form failure groove, so as to eliminate the compaction effect of rock. When designing the nozzle layout, it should avoid the damage of well-hole wall, while improving drilling efficiency. Therefore, the nozzle arrangement with single angle cannot meet the requirements of high-efficiency rock breaking; the combined design scheme with impact angle of $8^{\circ}$ and $20^{\circ}$ is suggested to be adopted in engineering experiment (the nozzle layout is shown in Figure 11), which can not only ensure the drilling speed but also prevent the well-hole wall from damage by the impact of particle jet and reflux flow. In this layout design of nozzle, the penetration speed of rock needs to be calculated with different angles from Figure 9, and

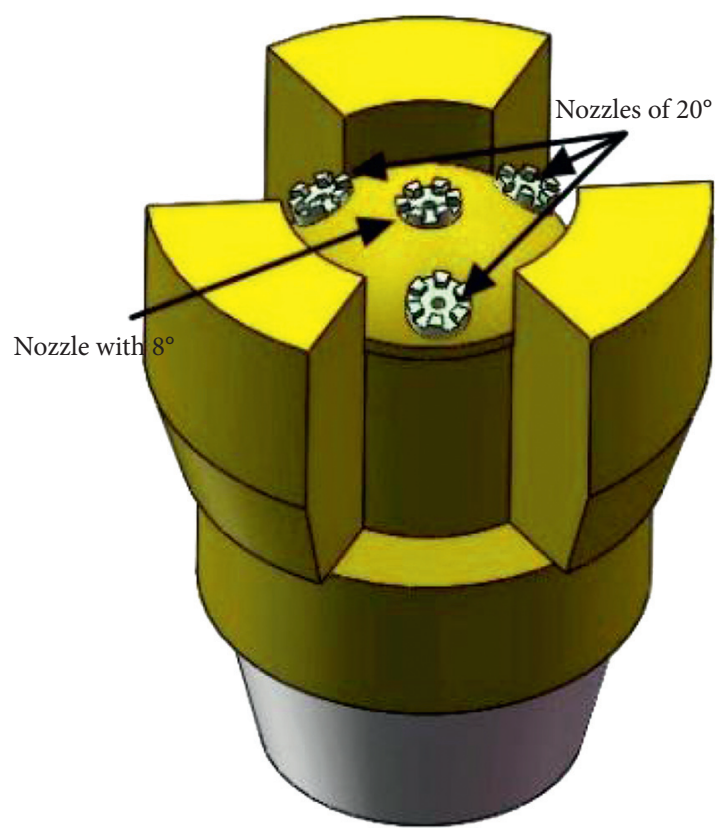

FIgURE 11: The nozzle layout.

for different angles of single nozzle, the penetration speed of rock at $8^{\circ}$ is about 2.5 times of $20^{\circ}$. Therefore, a nozzle with impact angle of $8^{\circ}$ and three nozzles with impact angle of $20^{\circ}$ are used to design bit, so that the penetration speed of inner ring and outer ring is basically identical.

4.3. Particle Diameter. In particle jet impact rock experiment, the impact kinetic energy and action area of particles with different diameters are also different, and particle diameter is also one of the important factors affecting rock failure. Therefore, the effect of particle diameter on rockbreaking depth and damage area was studied. The comparable results are shown in Figures 12 and 13, respectively.

From the curve of rock-breaking depth and damage area, it can be seen that, with increase of particle diameter, rockbreaking depth and damage area under particle jet impact both represent a downward trend. The reason is that, with increase of particle diameter, impact velocity of particle would decrease, and also the impact frequency would be reduced several times with particle ratio being constant. Therefore, the rock-breaking depth and damage area would increase with particle diameter being small, while too small diameter of particles will lead impact energy to be lower. Considering rock-breaking effect and impact energy, particles with diameter of $1.0 \mathrm{~mm}$ are preferable. Comparing the curves of rock-breaking depth and damage area, the average error is basically within 5\%, and the maximum error is less than $8 \%$. Overall, the trends of penetration depth and damage area are basically consistent; thus it verified the correctness of theory calculation model.

4.4. Analysis of Rock-Breaking Process. According to previous analysis, the rock-breaking experiment was carried out with such layout of nozzles shown in Figure 11 and the 


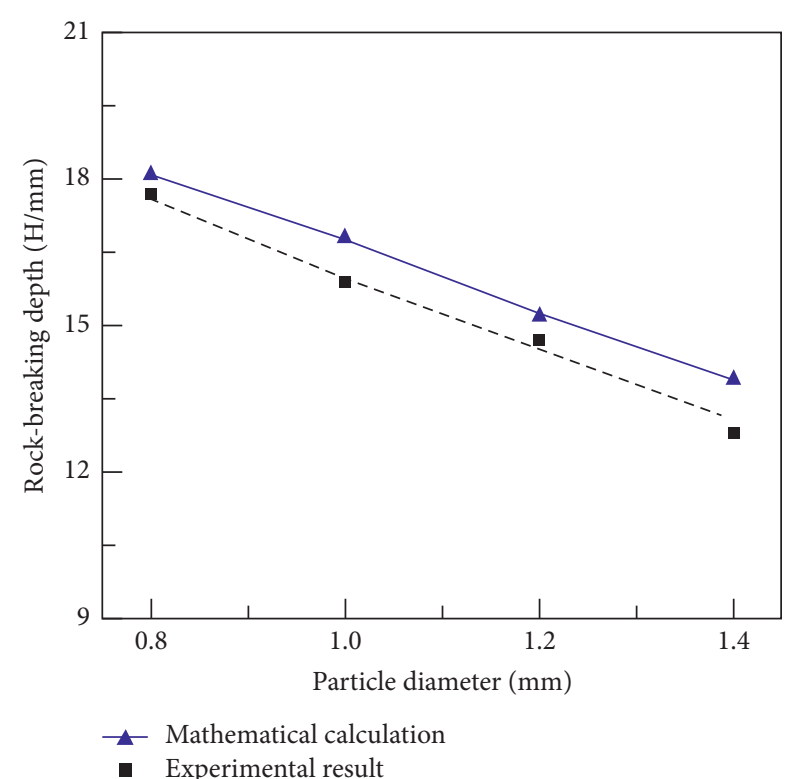

FIGURE 12: Effect of particle diameter on rock-breaking depth (test time with $10 \mathrm{~s}$; water-jet impact velocity with $205 \mathrm{~m} / \mathrm{s}$; impact angle with $8^{\circ}$ ).

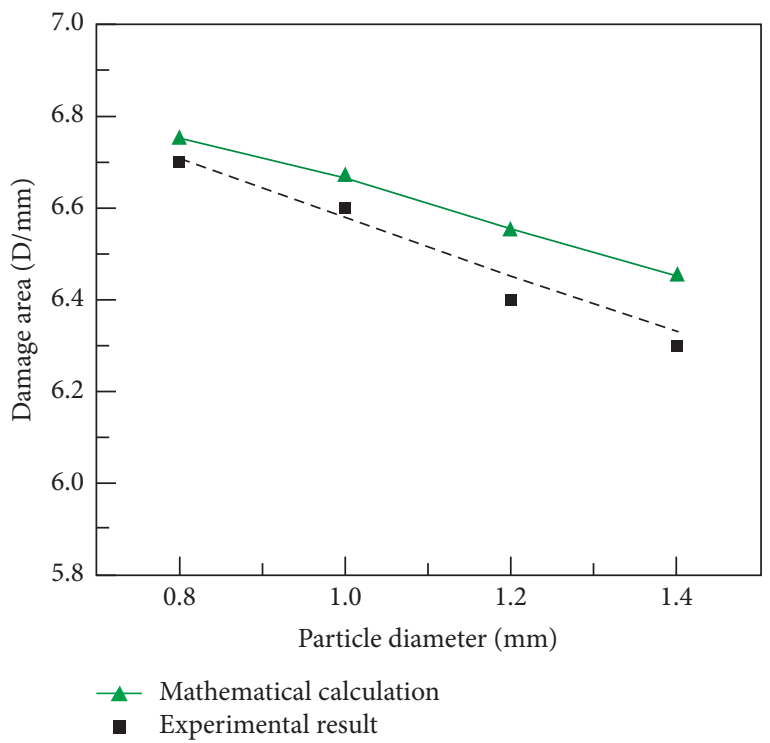

FIGURE 13: Effect of particle diameter on damage area (test time with $10 \mathrm{~s}$; water-jet impact velocity with $205 \mathrm{~m} / \mathrm{s}$; impact angle with $8^{\circ}$ ).

optimal selected parameters, and rock-breaking experimental sample is shown in Figure 14.

Particle jet impact drilling process can be divided into two parts: particle jet impact rock and mechanical drill bit cutting rock. Since the rock-cutting speed of drill bit is smaller than that of particle jet impact, particles and water jet would impact on rock to form the annular broken zone, releasing internal confining pressure of rock. Due to the existence of rock failure and damage under particle jet impact in deep well, mechanical drill bit could make it easier to be cut and crushed, thereby achieving the purpose of efficient drilling. Meanwhile, the broken zone of outer ring

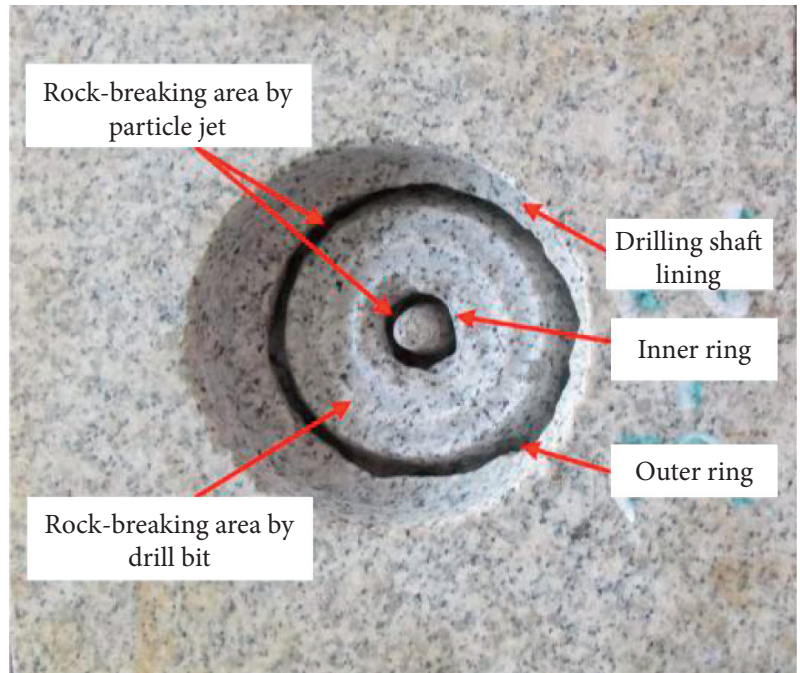

FIGURE 14: Analysis of rock-breaking sample.

has a certain distance from wall to avoid damage to wellbore. Therefore, particle jet impact drilling process enables rapid drilling of hard, abrasive-resistant formations.

\section{Conclusion}

(1) The experiment device of particle jet impact rock breaking was developed, and laboratory tests have been carried to obtain rock-breaking depth and damage area according to the operation process and measurement method.

(2) Based on spherical cavity expansion theory, the mathematical model of rock-breaking depth and damage area under particle jet impact is established. And the effects of water-jet impact velocity, particle diameter, and impact angle on rock-breaking depth and damage area are mathematically analyzed.

(3) The influence of water-jet impact velocity, impact angle, and particle diameter on rock-breaking depth and damage area is analyzed by comparing experimental research and mathematical calculation. Results show that rock-breaking depth and damage area would increase with increase of water-jet impact velocity and decrease with increase of particle diameter. The water-jet impact velocity of $200-210 \mathrm{~m} / \mathrm{s}$, particle diameter of $1.0 \mathrm{~mm}$, and combined angle of $8^{\circ}$ and $20^{\circ}$ can meet the requirements of rock breaking. The experiment and mathematical calculation results are basically consistent, which verifies the correctness of the model and can realize the determination of jet parameters and quantitative analysis of rock-breaking effect.

\section{Nomenclature}

$v_{p}$ : Particle velocity

$\eta$ : Ratio of particle velocity and water-jet velocity

$v_{w}$ : Water-jet velocity

$L_{0}^{w}$ : The length of nozzle contraction section 
$\sigma_{w}:$ Constant pressure of water jet

$\rho_{w}$ : Water-jet density

$Q_{w}$ : Flow rate of nozzle

$S_{A}$ : Collision area of water jet

$n$ : Impact frequency of unit area

$\omega_{p}$ : The incorporation speed of particle

$t_{p}$ : The incorporation time of particle

$V_{p}$ : Particle volume

$n_{p}$ : Particle numbers

$r$ : Radial coordinate of Euler coordinates

$\rho_{r}:$ Rock density

$\sigma_{r}:$ Radial stress

$\sigma_{\theta}:$ Tangential stress

$\sigma_{\phi}:$ Circumferential stress

$\delta_{c}$ : Compressive strength of rock

$\mu: \quad$ Coefficient of sliding friction

$\varepsilon: \quad$ Elastic strain

$\sigma_{r n}:$ Radial stress with rock damaged

$E_{r}$ : Rock elastic modulus

$E_{n}$ : Elastic modulus with rock damaged

$\eta^{*}$ : Volume compaction strain

$\delta_{t}$ : Rock shear strength

$D_{n}$ : Cumulative damage factor

$F_{h}$ : The sum of resistance in vertical direction

$R: \quad$ Particle radius

$\theta$ : The angle between microelement and $Z$-axis

$\beta$ : Impact angle

$u_{r}:$ Radial displacement

$\mu_{r}$ : Poisson's ratio of rock

$a$ : Spherical radius of cavity region

$b$ : Outer diameter of rock fracture region

$c$ : Outer diameter of crack region

$d$ : Outer diameter of elastic deformation region

$b_{j}$ : Damage region of water jet

$\sigma_{d}:$ Superimposed stress

$d_{n}$ : Nozzle diameter

$D$ : The damage area.

\section{Data Availability}

The data used to support the findings of this study are available from the corresponding author upon request.

\section{Conflicts of Interest}

The authors declare that there are no conflicts of interest.

\section{Acknowledgments}

This study was funded by the National Natural Science Foundation of China (11972113), the Postdoctoral Research Start-Up Fund Project of Heilongjiang Province (LBHQ15018), and the Guiding Innovation Fund Project of Northeast Petroleum University (2019YDL-07).

\section{References}

[1] H. Wang, Y. Ge, and L. Shi, "The present situation, challenges and development direction of ultra-deep well drilling and completion technology in deep well and ultra-deep well," Natural Gas Industry, vol. 37, pp. 1-8, 2017.

[2] A. W. Momber, "Fracture toughness effects in geomaterial solid particle erosion," Rock Mechanics and Rock Engineering, vol. 48, no. 4, pp. 1573-1588, 2015.

[3] A. Ramezanzadeh and M. Hood, "A state-of-the-art review of mechanical rock excavation technologies," Journal of Mining and Environment, vol. 1, pp. 29-39, 2010.

[4] Y. Lu, J. Tang, Z. Ge, B. Xia, and Y. Liu, "Hard rock drilling technique with abrasive water jet assistance," International Journal of Rock Mechanics and Mining Sciences, vol. 60, pp. 47-56, 2013.

[5] Y. Jia, Y. Lu, D. Elsworth, Y. Fang, and J. Tang, "Surface characteristics and permeability enhancement of shale fractures due to water and supercritical carbon dioxide fracturing," Journal of Petroleum Science and Engineering, vol. 165, pp. 284-297, 2018.

[6] Q. Geng, Z. Wei, F. He, and H. Meng, "Comparison of the mechanical performance between two-stage and flat-face cutter head for the rock tunnel boring machine (TBM)," Journal of Mechinical Science and Technology, vol. 29, pp. 2047-2058, 2015.

[7] Q. Geng, Z. Wei, H. Meng, F. J. Macias, and A. Bruland, "Freeface-Assisted rock breaking method based on the multi-stage tunnel boring machine (TBM) cutterhead," Rock Mechanics and Rock Engineering, vol. 49, no. 11, pp. 4459-4472, 2016.

[8] Y. M. Xia, B. Guo, G. Q. Cong, X. H. Zhang, and G. Y. Zeng, "Numerical simulation of rock fragmentation induced by a single TBM disc cutter close to a side free surface," International Journal of Rock Mechanics and Mining Sciences, vol. 91, pp. 40-48, 2017.

[9] T. Rupam, H. Sergej, C. Somnath, K. Dagmar, Š. Jiří, and K. D. Alok, "Application of the pulsating and continous water jet for granite erosion," International Journal of Rock Mechanics and Mining Sciences, vol. 126, Article ID 104209, 2020.

[10] H. Thomas, "Particle drilling pulverizes hard rocks," The American Oil \& Gas Reporter, vol. 50, pp. 86-89, 2007.

[11] M. Cui, Y. H. Zhai, and G. D. Ji, "Experimental study of rock breaking effect of steel particles," Journal of Hydrodynamics, vol. 23, no. 2, pp. 241-246, 2011.

[12] W. Li, T. Yan, Z. Zhang et al., "Rock response mechanism and rock breaking test analysis for impact of high frequency vibration drilling tool," Petroleum Drilling Techniques, vol. 41, pp. 25-28, 2013.

[13] J. Zhao, L. Han, Y. Xu et al., "Theory and field test of particle impact drilling technology," Natural Gas Industry, vol. 34, pp. 102-107, 2014.

[14] F. Ren, B. Wang, X. Cheng et al., "Design and experimental investigation about a simulation device for particle impact rock breaking," in Proceedings of the International Conference on Experimental Mechanics, Edinburg, TA, USA, September 2015.

[15] G. Li, H. L. Liao, Z. W. Huang et al., "Rock damage mechanisms under ultra-high pressure water jet impact," Journal of Mechanical Engineering, vol. 45, no. 10, pp. 284-293, 2009.

[16] T. Yan, M. Jiang, Y. Zhang et al., "Rock breaking by particle impact under confining pressure based on ansys-lsdyna," Fault Block Oil and Gas Field, vol. 19, pp. 240-243, 2012.

[17] R. Wang, Q. Xue, L. Han, F. Sun, and W. Yue, “Torsional vibration analysis of push-the-bit rotary steerable drilling system," Meccanica, vol. 49, no. 7, pp. 1601-1615, 2014.

[18] F. S. Ren, X. Z. Cheng, Y. Li et al., "Mathematical modeling and experimental analysis of coupled particles and water jet impact rock breaking," Engineering Mechanics, vol. 34, pp. 249-256, 2017. 
[19] J. Zhao, G. Zhang, Y. Xu et al., "Mechanism and effect of jet parameters on particle waterjet rock breaking," Powder Technology, vol. 313, pp. 231-244, 2017.

[20] F. Wang, R. Wang, W. Zhou, and G. Chen, "Numerical simulation and experimental verification of the rock damage field under particle water jet impacting," International Journal of Impact Engineering, vol. 102, pp. 169-179, 2017.

[21] K. S. Wu, J. f. Gu, Y. C. Kuang et al., "Comment on particle impact drilling technology," Journal of Southwest Petroleum University (Science \& Technology Edition), vol. 30, pp. 142146, 2008.

[22] Y. C. Kuang, Z. P. Zhu, H. J. Jiang et al., "The experimental study and numerical simulation of single-particle impacting rock," Acta Petrolei Sinica, vol. 17, pp. 779-788, 2012.

[23] S. Anwar, D. A. Axinte, and A. A. Becker, "Finite element modelling of overlapping abrasive waterjet milled footprints," Wear, vol. 303, no. 1-2, pp. 426-436, 2013.

[24] H. Jiang, Z. Liu, and K. Gao, "Numerical simulation on rock fragmentation by discontinuous water-jet using coupled sph/ fea method," Powder Technology, vol. 312, pp. 248-259, 2017.

[25] F. Ren, T. Fang, X. Cheng et al., "Rock-breaking stress analysis and rock-breaking region under particle-waterjet impact," Acta Petrolei Sinica, vol. 39, pp. 1070-1080, 2018.

[26] F. Wang, D. Zhou, Q. Xu, C. Qiang, and C. Guo, "Mathematical model of rock stress under abrasive slurry jet impact based on contact mechanics," International Journal of Rock Mechanics and Mining Sciences, vol. 107, pp. 1-8, 2018.

[27] X. Cheng, F. Ren, T. Fang et al., "Rock-breaking experiment of particle jet coupling impact," Acta Petrolei Sinica, vol. 39, pp. 232-239, 2018.

[28] F. Ren, T. Fang, and X. Cheng, "Parameter optimization and experimental study of particle jet impact rock breaking nozzle," China Petroleum Machinery, vol. 46, pp. 5-11, 2018.

[29] F. Ren, T. Fang, and X. Cheng, "Theoretical modeling and experimental study of rock-breaking depth in particle jet impact drilling process," Journal of Petroleum Science and Engineering, vol. 183, p. 106419, 2019.

[30] F. Ren, T. Fang, and X. Cheng, "Study on rock damage and failure depth under particle water-jet coupling impact," International Journal of Impact Engineering, vol. 139, p. 103504, 2020.

[31] V. K. Luk, M. J. Forrestal, and D. E. Amos, "Dynamic spherical cavity expansion of strain-hardening materials," Journal of Applied Mechanics, vol. 58, no. 1, pp. 1-6, 1991.

[32] S. Zhang, H. J. Wu, Z. J. Tan, and F. L. Huang, "Theoretical analysis of dynamic spherical cavity expansion in reinforced concretes," Key Engineering Materials, vol. 715, pp. 222-227, 2016.

[33] C. He, J. F. Jin, X. J. Zhou et al., "Damage constitutive model of rock subjected to coupled static loadings and cyclic impacts," Nonferrous Metals Science \& Engineering, vol. 7, pp. 114-120, 2016.

[34] T. Nguyen and Z. Gajic, "Solving the matrix differential riccati equation: a lyapunov equation approach," IEEE Transactions on Automatic Control, vol. 55, pp. 191-194, 2010.

[35] X. Xiao, X. Tong, G. Gao, R. Zhao, Y. Liu, and Y. Li, "Estimation of peening effects of random and regular peening patterns," Journal of Materials Processing Technology, vol. 254, pp. 13-24, 2018. 